\title{
Variation in the Incidence of Self-Immolation According To Culture and Income Level: A Literature Review
}

\section{Sarah $\mathrm{L}^{1,2}$ and Prat $\mathrm{SS}^{\star 3,4,5}$}

${ }^{1}$ Unité de consultation et de soins ambulatoires de la Maison d’Arrêt de Tours, Centre Hospitalo-Universitaire, Tours, France

${ }^{2}$ Urgences psychiatriques, Centre Hospitalo-Universitaire, Tours, France

${ }^{3}$ Department of Psychiatry and Behavioural Neurosciences, McMaster University, Hamilton, Canada

${ }^{4}$ Forensic Psychiatry Program, St Joseph's Healthcare, Hamilton, Canada

${ }^{5}$ E.A.2114 Psychologie des âges de la vie, Université François Rabelais, Tours, France

${ }^{*}$ Corresponding author: Prat SS, Forensic Psychiatry Program, McMaster University, St Joseph's Healthcare, Hamilton, Canada, Tel: +1 905522 1155, Fax : +1 (905) 381-5604, E-mail: prats@mcmaster.ca

Citation: Sarah L, Prat SS (2017) Variation in the Incidence of Self-Immolation According To Culture and Income Level: A Literature Review. J Forensic Sci Criminol 5(2): 203

Received Date: December 19, 2016 Accepted Date: April 19, 2017 Published Date: April 21, 2017

\begin{abstract}
Self-immolation is most commonly observed in the Middle East and Western Asia. It is far less common in the Western world. Documented cases in the West indicate that victims are more likely to be immigrants, indicating that there may be cultural influences that motivate this behavior. We have performed a literature review on self-immolation in order to better understand the cultural differences behind selfimmolation and the psychopathology related to this specific behavior.
\end{abstract}

Keywords: Forensic Medicine; Suicide; Attempted-suicide; Self-immolation; Self-burning; Cultural differences

\section{Introduction}

Self-immolation is an especially violent form of suicide because of the degree suffering during the act and the level of physical damage it causes. The impact on public opinion has allowed it to become a powerful tool in mobilizing mass movements such as in the "Jasmine Revolution" [1]. This form of suicide has historically been used as a way of expressing political dissent: in 1963 in Saigon by Bonz Thich Quang-Duc, in 1969 in Prague by Jan Palach, and in 1998 in Rome by Alfredo Ormando [2,3]. Immolation has been carried out as an isolated act by one person or even a group of people, sometimes through replication or what has been called the "copycat phenomenon" [4]. The epidemic nature of this phenomenon is often facilitated by the media, and has recently been documented in India, Sri Lanka and Iran [5-7]. However, it has also gained traction in countries like the UK where the rate of this method of suicide has increased over a one-year period [6].

Self-immolation is most commonly observed in the Middle East and Western Asia [5]. It is far less common in the Western world, where estimates place this method at $0.06 \%$ to $1.5 \%$ of all suicides and suicide attempts $[8,9]$. By contrast, estimates place the rate at as high as $40 \%$ in certain developing countries [5,7,10-12]. Despite the low overall rate in the Western world, self-immolation may represent 1 to $10 \%$ of the cases in Burn Units $[9,13]$. Documented cases in the West indicate that victims are more likely to be immigrants, indicating that there may be cultural influences that motivate this behavior [6,14-19].

We have performed a literature review on self-immolation in order to better understand the cultural differences behind selfimmolation and the psychopathology related to this specific behaviour.

\section{Materials and Methods}

For our review, we carried out a systematic search of the Medline, Pubmed and PsychInfo databases. Search terms included "autoimmolation", "self-burning", "self-immolation", and "suicide by fire". We selected studies and case reports and included papers dealing with both living and dead victims. We excluded papers dealing with minor burning-related self-harm behaviours that could not be linked to a suicide behavior, such as self-harm with cigarettes. We did not limit our search by date of publication.

From these initial results, we extracted sociodemographic data (sex, mean age, marital status, socio-professional environment), psychiatric data (diagnosis, inpatient admission, treatment), and medico-legal data surrounding the suicide act (location, 
precipitating factor, substance abuse, chemical substance use). The main objective was to highlight ethnic and geographical differences among victims of self-immolation and to offer a potential explanation for such differences.

Cultural and ethnic factors may be also be related to income level in different countries. Peck et al. suggested sorting data into low and medium-income countries for a better understanding of factors behind self-immolation [20,21]. Thus, we grouped our data based on income level (low-income countries vs high-income countries) according to the World Bank Classification (http://data. worldbank.org/about/country-and-lending-groups accessed on March 9th, 2015).

\section{Results}

We found 57 papers on self-immolation that contained information related to the victims' ethnic and geographic backgrounds. The papers were published between 1973 and 2015 [5,22]. We sorted our data based on the level of income of countries in order to make comparisons based on cultural background. The separation between low and high-income countries approximates the separation between Asian and African nations and countries from the Western world.

The majority of the studies contained epidemiological data. Sample sizes varied from 10 to 242 [23,24]. In order to be able to compare the studies, despite small sample sizes, we extrapolated the results in the form of percentages.

This literature review allowed the description of the sociodemographic data (ethnic and demographic; social instability and isolation), psychopathological data (psychiatric history; diagnosis; premeditation, impulsivity and intentionality) and data surrounding this type of suicidal behaviour (precipitating factor; substance abuse; location; chemical use). We have summarized the data in a table (Table 1). Results are detailed and commented on in the Discussion section. There did not appear to be any clear differences between low and high-income countries with regards to premeditation, lethal intentionality, and social vulnerability. However, we decided to include this data due to its relevance.

\begin{tabular}{|c|c|c|c|}
\hline & & $\begin{array}{l}\text { High-income countries/ } \\
\text { Western countries }\end{array}$ & $\begin{array}{c}\text { Low-income countries/ } \\
\text { Africa - Eastern } \\
\text { countries }\end{array}$ \\
\hline \multicolumn{2}{|c|}{ General profile } & $\begin{array}{c}\text { Male } \\
50 y-o\end{array}$ & $\begin{array}{c}\text { Female } \\
\text { Young adult }\end{array}$ \\
\hline \multirow{10}{*}{$\begin{array}{l}\text { Epidemiological } \\
\text { aspects }\end{array}$} & Sex & Mostly male & Mostly female \\
\hline & Age & $35-50 y-0$ & $25 y-0$ \\
\hline & Marital status & Unmarried (75-81\%) & $\begin{array}{l}\text { Young adult married } \\
\text { female }\end{array}$ \\
\hline & Unemployement & \multicolumn{2}{|c|}{$25-80 \%$} \\
\hline & Homeless & \multicolumn{2}{|c|}{$6-15 \%$} \\
\hline & $\begin{array}{c}\text { Unspecified psychiatric } \\
\text { disorder }\end{array}$ & \multicolumn{2}{|c|}{$58-83 \%$} \\
\hline & SA & \multicolumn{2}{|c|}{$20-69 \%$} \\
\hline & Psychotropic med & \multicolumn{2}{|c|}{$>50 \%$} \\
\hline & $\begin{array}{l}\text { Admission in } \\
\text { psychiatry }\end{array}$ & \multicolumn{2}{|c|}{$50 \%$} \\
\hline & Diagnosis & $\begin{array}{c}\text { Depression } \\
\text { Psychosis }(3-44 \%) \\
\text { Personnality disorder }(60 \%) \\
\text { Addiction }(25-59 \%)\end{array}$ & $\begin{array}{l}\text { Adjustment disorder } \\
\text { Depression } \\
\text { PTSD }\end{array}$ \\
\hline \multirow{3}{*}{ Behavioral aspects } & Lethal intentionnality & \multicolumn{2}{|c|}{$20-41 \%$} \\
\hline & Impulsivity & \multicolumn{2}{|c|}{$17-46 \%$} \\
\hline & Premeditation & \multicolumn{2}{|c|}{$22-26 \%$} \\
\hline \multicolumn{2}{|c|}{ Precipitating factor } & $\begin{array}{c}\text { Spouse conflict } \\
\text { Financial issues } \\
\text { (unemployment 65\%) }\end{array}$ & $\begin{array}{l}\text { Spousal conflict } \\
\text { Political and social } \\
\text { demands }\end{array}$ \\
\hline Drugs & $\begin{array}{l}\text { Alcohol } \\
\text { Other drugs }\end{array}$ & \multicolumn{2}{|c|}{$\begin{array}{c}13-50 \% \\
43 \%\end{array}$} \\
\hline \multicolumn{2}{|c|}{ Location } & Isolated place & In public \\
\hline \multicolumn{2}{|c|}{ Chemical use } & Gas & $\begin{array}{l}\text { Gas } \\
\text { Alcohol } \\
\text { Paraffin }\end{array}$ \\
\hline
\end{tabular}

Table 1: Summary of the data from the literature according to self-inflicted burns (y-o: years old; SA: suicide attempt; med: medication) ${ }^{1}$ Female victims are usually older than male victims 


\section{Discussion}

This literature review allowed us to construct two broad profiles of victims of self-immolation:

a) Males around 50 years of age, with a clear psychiatric disorder in the high-income countries

b) Young females with low levels of education for whom self-immolation is a response to circumstances in low-income countries.

These two profiles highlight specific sociodemographic, psychopathological, and circumstances surrounding self-immolation.

\section{Sociodemographic characteristics}

\section{Ethnic and epidemiological aspects}

Public self-immolation, which may be politically and socially motivated, is more frequent in Asia and the Middle East $[5,7,10,22,25,26]$. As stated earlier, self-immolation appears to be more common in those regions of the world. Higher rates by these same racial and ethnic groups may also been seen in immigrant populations [6,14-17]. There appears to be a higher rate of self-immolation committed by immigrants in England and South Africa, compared to the non-immigrant population. However these racial and ethnic differences have not been observed by studies conducted in the United States [18,19,27]. This difference might be interpreted as a result of variations in integration and whether ethnic community traditions persist more strongly in certain countries than in others.

In high-income countries, victims of self-immolation are mainly male, aged 37.4 to 50.2 years old [8,28-34]. The mean age is lower for self-immolation as compared to other methods of suicide. However, female victims are usually older than males.

In low-income countries, victims are typically young women or female adolescents [7,24,35-38].

\section{Social instability and isolation}

Social instability and isolation seem to be common criteria of all the victims, regardless of their country of origin. Unemployment is described in 25 to $80 \%$ of cases, and is sometimes associated with a lower level of education [9,18,23,32,39-41]. This appears to be more common with male victims. Isolation has also been described in 6 to $15 \%$ of cases, with higher rates found in homeless or incarcerated populations $[18,32]$.

In high-income countries, 75 to $81 \%$ of victims lived alone $[8,18,27,40]$.

In low-income countries, social vulnerability applies mainly to women, because of their low education level and illiteracy that contribute to their dependence on their spouses or in-laws $[10,11,42,43]$. The victims are usually young married women, and the suicide act is committed around 5 to 6 years after marriage [10]. The birth-order of the victims might also be linked to the act of committing suicide. According to Ahmadi et al. both the eldest or the youngest siblings are at a higher risk of suicide [11]. The hypothesis is tied to familial pressures of having a successful marriage. Domestic violence and dependence on a partner due to lack of education are commonly described. On the other hand, being married with several children seems to reduce the risk of suicide for such women.

\section{Psychopathology}

\section{Psychiatric history}

The majority of the data related to the psychiatric history of victims has been collected from surveys of high-income countries.

In high-income countries, psychiatric history is present in 60 to $83 \%$ of victims and familial psychiatric history in $60 \%$ [8,27,28,33]. Victims have received psychiatric medication and have been admitted to a psychiatric facility in more than half of cases [31,33,44]. Previous suicide attempts prior to the immolation event are found in 20 to $69 \%$ of cases, but the specific act of immolation is often the first time attempt for victims $[8,18,32,33]$. This raises the question of the escalation of methods in committing suicide. No study describes a case of a second-time attempt of immolation after a non-lethal first attempt by immolation.

In low-income countries, as we described with the typology of the female victim, we hypothesize that the circumstances surrounding marriage might trigger mental instability. Therefore, we could assume that there is no significant psychiatric history prior to the event, in contrast to the typical victims in the high-income countries. However, it may be valuable to explore the influence of marriage in more depth in order to better understand which victims are more or less vulnerable in such situations. Zor., et al. described a small sample of ten victims of self-burning, involved in the military, who all had psychiatric history and a diagnosis of personality disorder [23].

\section{Psychiatric diagnosis}

The psychiatric diagnoses of the victims differ according to their backgrounds, which may shed light on the reasons behind their suicide attempts. 
In high-income countries, major depressive episode is the most common diagnosis, with or without psychotic features and substance abuse $[8,10,18,27,29,31,32,45-47]$. Other diagnoses include psychotic episodes in 3 to $44 \%$, personality disorder in $60 \%$ and substance abuse in 25 to $59 \%$ [8,9,18,19,23,27,29,41,45].

In low-income countries, a psychiatric diagnosis is less often described. The lack of accessibility to care due to the isolation may be a reason for the absence of previous diagnosis and history of treatment. When victims are diagnosed, it is usually with adjustment disorder in depressive episode or PTSD [11,20,21]. Male victims in low-income countries seem to have higher rates of substance abuse disorder, especially alcoholism [11].

\section{Lethal intentionality, premeditation and impulsivity}

Our review has not been able to identify any clear information about intentionality, premeditation and impulsivity toward the suicidal behaviour in low-income countries. However, such factors are worth further investigation due to their potential impact on the mental status assessment and ability to predict the risk of this type of self-harm.

Self-harming behaviour with violent methods is not necessarily linked to a true lethal intent. Often this intent can also fluctuate according to the emotion dysregulation of personality disorder. A true intent to die is described in only 20 to $41 \%$ of cases $[19,27,32,48-50]$. Impulsivity as the reason behind the decision to commit suicide is present in 17 to $46 \%$ of cases, whereas premeditation is found in 22 to $26 \%$ of cases [27,40,51,52].

\section{Circumstances surrounding self-harming behavior}

\section{Precipitating factors}

Emotional dysregulation and economic concerns appear to be the main motives behind self-immolation. Emotional dysregulation is related to issues, such as break-ups, infidelity, or spousal violence [11,29,32,33,35,37,38]. Motives such as social isolation are also described $[18,27]$. Intra-familial conflict and financial issues are described in both low and high-income countries $[7,11,20,21,29,32,33,35,52]$.

In high-income countries, economic concerns (approximately 65\% of victims found to be unemployed) are the main motives $[18,29,33]$.

In low-income countries, we identified arranged marriages, spousal violence and political reasons as the motives [20,21,37,38,53].

\section{Substance abuse}

The majority of studies describing drug abuse and self-immolation have been conducted in high-income countries [13,19,29,32,33]. Alcohol use is found in 13 to 50\% of cases and toxic levels of drugs are found in 25 to 43\% [19,29,32,33,40,52]. According to some studies, more than half of the victims were found to be on psychiatric medication at the time of the event, explaining the victims' easy access to such substances $[31,33,44]$.

\section{Location}

Home is the main location for immolation, described in 50 to $65 \%$ of the cases $[8,17,28,29,31-33,38]$. Some psychopathological characteristics may influence this choice of location. Many victims meet the criteria for a cluster $\mathrm{C}$ personality disorder, and this may explain their preference to commit immolation in a public area [23]. Furthermore, compared to in high-income countries, in low-income countries the event may take place in public areas as a way of expressing political dissent [7,10,20,21]. We must also bear in mind that the influence of isolation and social vulnerability, which people may experience when they are hospitalized or incarcerated. These factors has been observed to motivate victims to use fire to commit suicide, in both low and high-income countries $[31,40,45,54]$. In controlled environments, where many items are banned for safety, fire may be the only means available for suicide, and therefore exists as the default tool for suicide attempts because of lack of access to less lethal methods such as medications for overdose.

\section{Chemical use to facilitate the ignition}

Using an inflammable product has an impact on the gravity of injuries and lethality. The use of such products is frequently described in the literature, in 30 to $77 \%$ of the victims $[8,13,19,26,28-30,32,33,35,39,55,56]$. According to Wiechman et al., inflammable product use is linked to suicide and lethal intentionality, compared to self-harming behavior where cigarette and matches are used more commonly instead [49].

In high-income countries, gas is the most common product used $[8,13,19,28-30,32,33]$.

In low-income countries, gas, alcohol and paraffin use is described [17,19,35,37].

\section{Conclusion}

This literature review allowed us to compare the differences between the victims of immolation in high and low-income countries. As described above, motives and sociodemographic characteristics are the main differences. There is little information on differences in psychopathology and this element needs to be studied in more depth [52]. Major burns may be a result of crime, suicide or 
accident. It is important to identify individuals with this type of suicidal ideation and behavior to adapt treatment and prevent future harm $[8,26,57]$. The immigration status and ethnic background of victims may represent an important clinical consideration in identifying the triggers behind such suicide attempts. Medical teams need to be able to tailor their care to the backgrounds and specific needs of patients, in order to successfully treat and rehabilitate victims of immolation.

\section{References}

1. Lim M (2013) Framing Bouazizi: "White lies", hybrid network, and collective/connective action in the 2010-11 Tunisian uprising. Journalism 14: $921-941$.

2. Biggs M (2005) Dying without killing: self-immolations, 1963-2002. In: Gambetta D (editor). Making sense of suicide missions. Oxford, Oxford University Press 173-208.

3. Boylan A (2013) Unresolved commemorations: memorials to victims of homophobic violence in Italy. The Italianist 33: 138-157.

4. Greenberg B, Strous RD (2012) Werther's syndrome: copycat self-immolation in Israel with a call for responsible media response. Isr Med Assoc J 14: 467-469.

5. Rezaeian M (2015) Self-immolation as a proxy measure for unmet needs among the vulnerable. Burns 41:17-418.

6. Ashton JR, Donnan S (1981) Suicide by burning as an epidemic phenomenon: an analysis of 82 deaths and inquests in England and Wales in 1978-9. Psychol Med 11: 735-739.

7. Laloë V (2004) Patterns of deliberate self-burning in various parts of the world. Burns 30: 207-215.

8. Gauthier S, Reisch T, Bartsch C (2014) Self-burning -a rare suicide method in Switzerland and other industrialised nations - a review. Burns 40: 1720-1726.

9. Palmu R, Isometsä E, Suominen K, Vuola J, Leppävuori A, et al. (2004) Self-inflicted burns: an eight year retrospective study in Finland. Burns 30: 443-447.

10. Poeschla B, Combs H, Livingstone S, Romm S, Klein MB (2011) Self-immolation: Socioeconomic, cultural and psychiatric patterns. Burns 37: $1049-57$.

11. Ahmadi A (2007) Suicide by self-immolation: comprehensive overview, experiences and suggestions. J Burn Care Res 28: 30-41.

12. Badiye A, Kapoor N, Ahmed S (2014) An empirical analysis of suicidal death trends in India: a 5 year retrospective study. J Forensic Leg Med 27: 29-34.

13. Franchitto N, Faurie C, Franchitto L, Minville V, Telmon N (2011) Self-inflicted burns: the value of collaboration between medicine and law. J Forensic Sci 56: 638-642.

14. Davidson TI, Brown LC (1985) Self-inflicted burns: a 5-year retrospective study. Burns 11: 157-160.

15. Prosser D (1996) Suicides by burning in England and Wales. Br J Psychiatry 168: 175-182.

16. Soni Raleigh V, Balarajan R (1992) Suicide and self-burning among Indians and West Indians in England and Wales. Br J Psychiatry 161: 365-368.

17. Sukhai A, Harris C, Moorad RGR, Dada MA (2002) Suicide by self-immolation in Durban, South Africa: a five-year retrospective review. Am J Forensic Med Pathol 23: 295-298.

18. Pham TN, King JR, Palmieri TL, Greenhalgh DG (2003) Predisposing factors for self-inflicted burns. J Burn Care Rehabil 24: 223-227.

19. Squyres V, Law EJ, Still JM Jr (1993) Self-inflicted burns. J Burn Care Rehabil 14: 476-479.

20. Peck MD (2012) Epidemiology of burns throughout the World. Part II: intentional burns in adults. Burns 38: 630-637.

21. Peck MD (2011) Epidemiology of burns throughout the world. Part I: distribution and risk factors. Burns 37: 1087-1100.

22. Topp DO (1973) Fire as a symbol and as a weapon of death. Med Sci Law 13: 79-86.

23. Zor F, Deveci M, Bozkurt M, Dikkatli S, Duman H (2005) Psychological evaluation of self-inflicted burn patients: suicide or parasuicide? Burns 31: 178-181.

24. Ambade VN, Godbole HV, Kukde HG (2007) Suicidal and homicidal deaths: a comparative and circumstantial approach. J Forensic Leg Med 14: 253-260.

25. Singh SP, Santosh PJ, Avasthi A, Kulhara P (1998) A psychosocial study of "self-immolation" in India. Acta Psychiatr Scand 97: 71-75.

26. Forster NA, Nuñez DG, Zingg M, Haile SR, Künzi W, et al (2012) Attempted suicide by self-immolation is a powerful predictive variable for survival of burn injuries. J Burn Care Res 33: 642-8.

27. Daniels SM, Fenley JD, Powers PS, Cruse CW (1991) Self-inflicted burns: a ten-year retrospective study. J Burn Care Rehabil 12: 144-147.

28. Cave Bondi G, Cipolloni L, Parroni E, Cecchi R (2001) A review of suicides by burning in Rome between 1947-1997 examined by the Pathology Department of the Institute of Forensic Medicine, University of Rome "La Sapienza". Burns 27: 227-231.

29. Makhlouf F, Alvarez J-C, de la Grandmaison GL (2011) Suicidal and criminal immolations: an 18-year study and review of the literature. Leg Med 13: 98-102. 30. Malic CC, Karoo ROS, Austin O, Phipps A (2007) Burns inflicted by self or by others--an 11 year snapshot. Burns 33: 92-97.

31. Castellani G, Beghini D, Barisoni D, Marigo M (1995) Suicide attempted by burning: a 10-year study of self-immolation deaths. Burns 21: 607-609.

32. Squires TJ, Busuttil A (1996) Suicide by fire in Scotland: 1980-1990. J Clin Forensic Med 3: 81-85.

33. Rothschild MA, Raatschen HJ, Schneider V (2001) Suicide by self-immolation in Berlin from 1990 to 2000. Forensic Sci Int 124: 163-166.

34. Nakae H, Zheng YJ, Wada H, Tajimi K, Endo S (2003) Characteristics of self-immolation attempts in Akita Prefecture, Japan. Burns 29: 691-696.

35. Mzezewa S, Jonsson K, Aberg M, Salemark L (2000) A prospective study of suicidal burns admitted to the Harare burns unit. Burns 26: 460-464.

36. Ganesamoni S, Kate V, Sadasivan J (2010) Epidemiology of hospitalized burn patients in a tertiary care hospital in South India. Burns 36: 422-429.

37. Natarajan M (2014) Differences between intentional and non-intentional burns in India: Implications for prevention. Burns 40: 1033-1039.

38. Rasool IA, Payton JL (2014) Tongues of fire: women's suicide and self-injury by burns in the Kurdistan Region of Iraq. Sociol Rev 62: 237-254.

39. Ali SN, Soueid A, Rao K, Moiemen N (2006) Self-inflicted burns, outcome and cost. Burns 32:63-466.

40. Seoighe DM, Conroy F, Hennessy G, Meagher P, Eadie P (2011) Self-inflicted burns in the Irish National Burns Unit. Burns 37: 1229-1232.

41. Kamolz L-P (2013) Attempted suicide by self-immolation is a powerful predictive variable for survival of burn injuries. J Burn Care Res 34: e271.

42. Raj A, Gomez C, Silverman JG (2008) Driven to a fiery death--the tragedy of self-immolation in Afghanistan. N Engl J Med 358: $2201-2203$.

43. Das Gupta SM, Tripathi CB (1984) Burnt wife syndrome. Ann Acad Med Singapore 13: 37-42.

44. Mulholland R, Green L, Longstaff C, Horner B, Ross E, et al (2008) Deliberate self-harm by burning: a retrospective case controlled study. J Burn Care Res 29: 644-649. 
45. O’Donoghue JM, Panchal JL, O’Sullivan ST, O’Shaughnessy M, O’Connor TP, et al (1998) A study of suicide and attempted suicide by self-immolation in an Irish psychiatric population: an increasing problem. Burns 24: 144-146.

46. Horner BM, Ahmadi H, Mulholland R, Myers SR, Catalan J (2005) Case-controlled study of patients with self-inflicted burns. Burns 31: $471-475$.

47. Thombs BD, Bresnick MG, Magyar-Russell G (2007) Who attempts suicide by burning? An analysis of age patterns of mortality by self-inflicted burning in the United States. Gen Hosp Psychiatry 29: 244-250.

48. Wallace KL, Pegg SP (1999) Self-inflicted burn injuries: an 11-year retrospective study. J Burn Care Rehabil 20: 191-194.

49. Wiechman SA, Ehde DM, Wilson BL, Patterson DR (2000) The management of self-inflicted burn injuries and disruptive behavior for patients with borderline personality disorder. J Burn Care Rehabil 21: 310-317.

50. Henderson A, Wijewardena A, Streimer J, Vandervord J (2013) Self-inflicted burns: a case series. Burns 39: 335-340.

51. Swenson JR, Dimsdale JE (1990) Substance abuse and attempts at suicide by burning. Am J Psychiatry 147: 811.

52. Hahn AP, Jochai D, Caufield-Noll CP, Hunt CA, Allen LE, (2014) Self-inflicted burns: a systematic review of the literature. J Burn Care Res 35: 102-119.

53. Boostani D, Abdinia S, Rahimipour Anaraki N (2013) Women victims of self-immolation: a “Grounded Theory” study in Iran. Qual Quant 47: 3153-65.

54. Andreasen NC, Noyes R (1975) Suicide attempted by self-immolation. Am J Psychiatr 132: 554-6.

55. Rashid A, Gowar JP (2004) A review of the trends of self-inflicted burns. Burns 30: 573-6.

56. Krummen DM, James K, Klein RL (1998) Suicide by burning: a retrospective review of the Akron Regional Burn Center. Burns 24: 147-9.

57. Laborderie S, Prat SS (2014) Aspect suicidaires, criminels et accidentels des décès par immolations : une revue de la littérature. Rev Med Leg 5: 148-59.

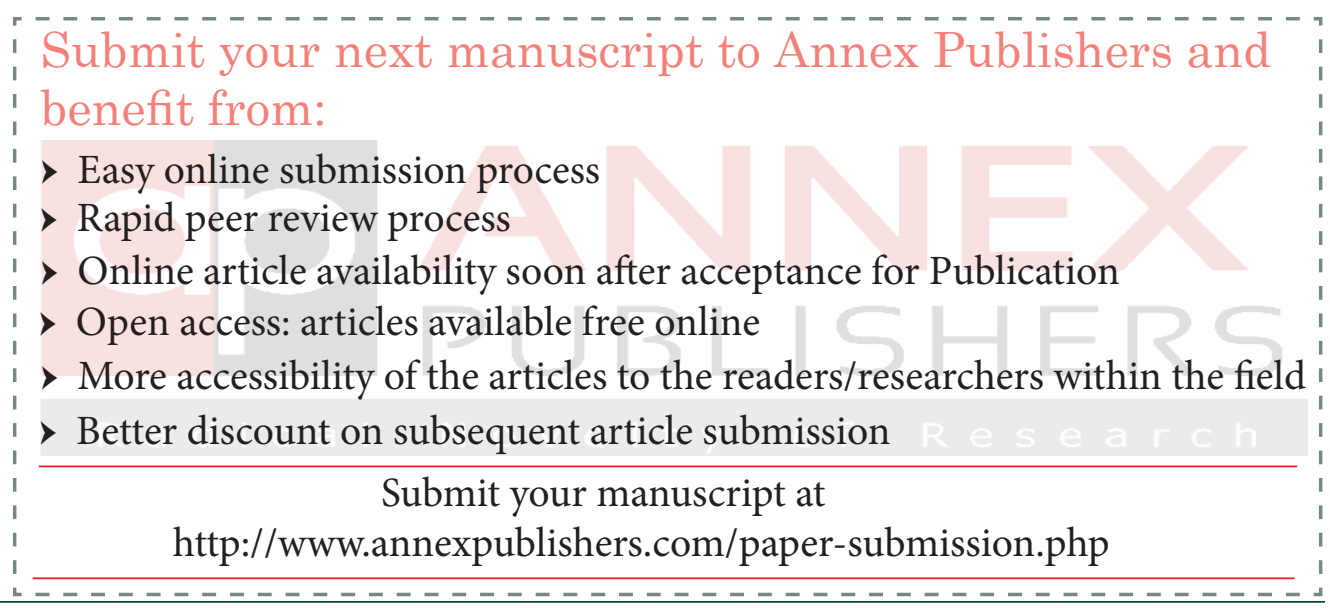

